REGHIN, M.Y.; OTTO, R.F.; SILVA, J.B.C. da. "Stimulate Mo" e proteção com "Tecido não Tecido" no pré-enraizamento de mudas de mandioquinha-salsa. Horticultura Brasileira, Brasília, v. 18, n. 1, p.53-56, março 2.000.

\title{
“Stimulate Mo" e proteção com Tecido "Não Tecido" no pré-enraizamento de mudas de mandioquinha-salsa.
}

\author{
Marie Yamamoto Reghin ${ }^{1}$; Rosana Fernandes Otto ${ }^{1}$; João Bosco Carvalho da Silva ${ }^{2}$ \\ ${ }^{1}$ UEPG-Dept $^{\circ}$ de Fitotecnia/Fitossanidade, C. Postal 992, 84.010-300 Ponta Grossa-PR; ${ }^{2}$ Embrapa Hortaliças, C. Postal 218, 70.359-970 \\ Brasília-DF.
}

\section{RESUMO}

Avaliou-se a brotação e o enraizamento de mudas de mandioquinha-salsa, cultivar Amarela Comum, tratadas com o composto de reguladores de crescimento "Stimulate Mo", associado ou não à cobertura dos canteiros com tecido de polipropileno, conhecido como Tecido "Não Tecido" (NT). As doses de "Stimulate Mo" foram: 1) testemunha sem tratamento; 2) $2,5 \mathrm{ml} / \mathrm{L}$; 3) $5,0 \mathrm{ml} / \mathrm{L}$; 4) $7,5 \mathrm{ml} / \mathrm{L}$ e 5) $10,0 \mathrm{ml} / \mathrm{L}$. As mudas foram retiradas da periferia da touceira, selecionadas por peso (10-15 g), cortadas em bisel (1,5-2,0 cm de comprimento) e tratadas com imersão em hipoclorito de sódio $10 \%$, por três minutos. Posteriormente foram imersas na solução de "Stimulate Mo", por 30 minutos, armazenadas à sombra por cinco dias e transferidas para canteiros. O NT foi colocado após o plantio, em cobertura do canteiro, como uma manta flutuante. Foram avaliados: porcentagem de mudas com brotação, número e comprimento de folhas e de raízes. Não houve interação significativa entre os fatores NT e doses de "Stimulate Mo". Observou-se efeito benéfico da proteção com NT para todas as características avaliadas, resultando em mudas uniformes, precoces e vigorosas aos 36 dias do plantio. O produto "Stimulate Mo" foi eficiente no aumento do número e comprimento de raízes, confirmando sua utilidade como estimulador do enraizamento.

Palavras-chave: Arracacia xanthorrhiza Bancroft, polipropileno, reguladores de crescimento.

\begin{abstract}
"Stimulate Mo" and protection with floating rowcover on pre-rooting of Peruvian carrot (Arracacia xanthorrhiza Bancroft) explants.

It was evaluated the effect of doses of Stimulate Mo, a product with growth regulators on the sprouting and pre rooting of Peruvian carrot explants, cultivar Amarela Comum, associated with and without floating rowcover of polypropylene. The following doses were tested: 1) 0 (control without treatment); 2) $2.5 \mathrm{ml} / \mathrm{L}$; 3) $5.0 \mathrm{ml} /$ $\mathrm{L}$; 4) $7.5 \mathrm{ml} / \mathrm{L}$ and 5) $10.0 \mathrm{ml} / \mathrm{L}$. The explants were removed from the cornels, selected by size $(10-15 \mathrm{~g})$, cut in bezel $(1.5-2.0 \mathrm{~cm}$ of length) and treated by immersion in sodium hypocloride $10 \%$ during three minutes. Afterwards the explants were treated in different dose of "Stimulate Mo" during 30 minutes and stored during five days in a shaded place. After planting the floating rowcover of polypropylene had been set, it was evaluated the percentage of explants with sprouting, number and length of leaves and number and length of roots. It was not observed significative effect of interaction between floating rowcover and doses of "Stimulate Mo". The protection by floating rowcover was superior in all of the characteristics observed, promoting the development of uniforms and vigorous explants and early pre-rooting at 36 days after planting. The product "Stimulate Mo" was efficient to increase number and root length confirming its utility as a rooting stimulator.
\end{abstract}

Keywords: Arracacia xanthorrhiza Bancroft, rooting, polypropylene, plant growth regulators.

\section{(Aceito para publicação em 10 de janeiro de 2.000)}

$\mathrm{O}$ Brasil é o maior produtor mundial de mandioquinha-salsa, cultivando-se anualmente cerca de 11.000 ha, com produtividade média de 9,2 t/ha. É um produto muito valorizado, tanto do ponto de vista nutricional quanto comercial, mas tem como principais inconvenientes o ciclo cultural relativamente longo (10 a 12 meses) e ser um produto muito perecível.

A cultura geralmente é instalada através de mudas ou rebentos que crescem a partir da base das plantas, formando uma touceira. A planta produz sementes botânicas, mas sua utilização é restrita aos trabalhos de melhoramento genético.

Pelo fato do ciclo da cultura ser longo, é necessário estabelecer tão rápido quanto possível, a população final desejada (Câmara, 1992). Por isso é importante conhecer bem os efeitos do tipo, tamanho das mudas, posição ocupada pela muda na touceira, tratamentos fitossanitários e técnicas para promover o rápido crescimento do vegetal, com maior garantia de estande.

Quando se referem à posição da muda na touceira, alguns autores (Silva \& Normanha, 1964; EMBRATER/ EMBRAPA, 1982), recomendam o uso daquelas da periferia, por resultarem em menor taxa de florescimento no campo. Câmara (1992), comparou mudas das regiões periférica, mediana e apical e enraizadas por 60 dias em canteiros, observando que o enraizamento destas e a produção de raízes de reserva por planta não foram influenciados pela posição do rebento na touceira. O autor concluiu que os fatores que regulam o florescimento não são os mesmos que condicionam as falhas de enraizamento no campo. Vieira et al. (1995) estudaram três tipos, três tamanhos e duas formas de plantio de mudas e seus efeitos no crescimento e produção da mandioquinha-salsa, quando observaram que a produção de raízes comerciáveis foi independente do tipo e tamanho de mudas utilizadas no plantio. Observaram ainda, quanto à profundidade da muda transplantada, que é mais viável deixar as mudas com o ápice descoberto no momento do plantio. 
Uma das práticas generalizadas no preparo das mudas nos países andinos e no Brasil que tem resultado em maior produção é o corte dos propágulos (Casali et al., 1984), reduzindo sua estrutura de reserva para 1,5 a 2,0 cm, com massa de 3,0 a 6,0 g. Quanto aos tipos de cortes, podem ser encontradas várias alternativas. O mais comum é o corte em bisel simples, que é feito com um único corte inclinado em relação ao eixo do comprimento da muda. Conforme Senna Neto (1976), esta forma aumenta a superfície cortada, proporcionando maior enraizamento e produtividade e menor pendoamento.

Na safra 96/97, no Estado do Paraná foram produzidas $39.827 \mathrm{t}$ (Seab, 1998), estando a cultura em plena expansão. Para o plantio da mandioquinha-salsa tem sido observado a seleção de touceiras, preparo das mudas e plantio em leiras, no local definitivo. Dependendo da época de plantio, principalmente no período da estação seca e fria tem-se verificado alta desuniformidade no estande, e percentual significativo de florescimento, com reflexos diretos na diminuição do rendimento da cultura. Conforme Santos (1997), os plantios comerciais de mandioquinha-salsa nas principais regiões produtoras do país apresentam perdas de produção devido ao florescimento que, em alguns casos, chega a causar reduções expressivas. Ocorrem dois tipos de florescimento: o primeiro, denominado "capitão" dá origem a plantas incapazes de produzir raízes de reserva; acredita-se que esse tipo de florescimento está associado a mudas mais velhas. O outro tipo de florescimento não vem a ser tão comprometedor na produção, uma vez que, apesar da emissão do pendão floral, há formação de brotações laterais, de tal forma que a planta completa seu ciclo normal, produzindo ainda raízes comerciais.

Câmara (1992) propôs conduzir a cultura em duas etapas, sendo a primeira destinada a promover o enraizamento de mudas, utilizando-se espaçamento adensado em canteiros, e a etapa definitiva instalada com o transplante das mudas pré-enraizadas. Isso possibilita evitar falhas no estande, selecionar plantas e manejar melhor a cultura, sem ocorrência de pendoamento e com menor tempo da cultura na área definitiva.

São poucos os resultados encontrados com reguladores de crescimento no pré-enraizamento de mudas de mandioquinha-salsa. Câmara (1989) estudou o enraizamento de mudas em substratos de areia, terra e vermiculita e suas misturas, imergindo previamente as mudas preparadas (corte transversal) em solução de ácido indol butírico (AIB) a 500, 1000 e 2000 ppm, por 20 segundos. Observou-se que o AIB, a partir de 1000 ppm, foi fitotóxico. A concentração de 500 ppm apresentou porcentagem média de enraizamento de $95 \%$, estatisticamente igual à testemunha, sem utilização de AIB. Nos tratamentos com AIB, sempre que houve presença de vermiculita no substrato, foi baixa a porcentagem de enraizamento. Entretanto, sem AIB, os substratos não se diferenciaram. Sendo assim, por meio dos resultados obtidos, para o enraizamento prévio, o autor recomenda quaisquer dos substratos utilizados, sem aplicação de AIB.

Em ensaio com mudas de mandioquinha-salsa, conduzido em casa-de-vegetação, Carvalho \& Leal (1997) observaram que os tratamentos com hormônio AIB em diversas dosagens e tempo de imersão, praticamente não influenciaram nas características estudadas (número de mudas vivas, sem podridões e número de mudas com brotações aos 15, 30 e 60 dias).

O produto "Stimulate Mo" é composto de reguladores de crescimento, contendo $90 \mathrm{ppm}$ de cinetina, $50 \mathrm{ppm}$ de ácido giberélico, 50 ppm de ácido indol butírico e 4\% de molibdênio (Stoller do Brasil, 1998). Sua função é estimular o desenvolvimento do sistema radicular, aumentando a absorção de água e nutrientes pelas plantas e favorecendo o equilíbrio hormonal. $\mathrm{O}$ crescimento contínuo das raízes é fundamental para a produção das citocininas, que só ocorrem na extremidade de raízes novas (Stoller do Brasil, 1998). Na literatura, não existem trabalhos nesta área com a cultura da mandioquinha-salsa. Contudo, tem-se informações de que alguns produtores do Paraná tratam os propágulos antes do plantio, com a dose de $5,0 \mathrm{ml} / \mathrm{L}$ de Stimulate Mo, durante 30 minutos.

O Tecido "Não Tecido" (NT) é um filme de polipropileno, confeccionado a partir de longos filamentos de polipropileno que são colocados em camadas e soldados uns aos outros por meio de calor. Tem ampla utilização na indústria têxtil no Brasil, mas sua utilidade na agricultura é ainda pouco conhecida. Entretanto, na Europa, estima-se em 20.000 ha a área de cultura e coberta com o NT (Hernandez \& Castilla, 1993). Esta "manta térmica" poderá, em muitos casos, se constituir em interessante alternativa de proteção de cultivos hortícolas, a baixo custo. Seu emprego é bastante generalizado em sementeiras (Hernandez \& Castilla, 1993), tais como a de fumo (Wells \& Loy, 1985), sendo colocado diretamente sobre o solo plantado, sem necessidade de estruturas de sustentação. Algumas vantagens atribuídas ao emprego do NT são o aumento da precocidade; aumento da produção (Soltani et al., 1995; Otto, 1997) e proteção contra danos causados por chuvas fortes ou granizo (Hemphill \& Crabtree, 1988).

O presente trabalho teve com o objetivo avaliar o efeito de doses de "Stimulate Mo", com e sem proteção de NT, no pré-enraizamento de mudas de mandioquinha-salsa.

\section{MATERIAL E MÉTODOS}

Propágulos de mandioquinha-salsa da cultivar "Amarela Comum" foram retirados da periferia das touceiras que completaram o ciclo vegetativo. Foram selecionados aqueles com massa de 10 a $15 \mathrm{~g}$, cortados em bisel a 1,5 - 2,0 cm da base das folhas e submetidos ao tratamento de imersão por três minutos, em solução à base de hipoclorito de sódio a 10\% (Brune et al., 1996). Posteriormente, os propágulos foram imersos por 30 minutos na solução de "Stimulate Mo", nas seguintes doses: 1 ) testemunha (sem tratamento); 2) $2,5 \mathrm{ml} / \mathrm{L}$; 3) $5,0 \mathrm{ml} / \mathrm{L}$; 4) $7,5 \mathrm{ml} / \mathrm{L}$ e 5) $10,0 \mathrm{ml} / \mathrm{L}$. Os propágulos foram mantidos em condições ambientais de laboratório por cinco dias, para cicatrização do tecido cortado, e então transferidos para canteiros com $1 \mathrm{~m}$ de comprimento por $1,1 \mathrm{~m}$ de largura, no espaçamento de 0,05 x 0,05 $\mathrm{m}$, com 56 mudas por parcela. Em seguida os canteiros foram, ou não cobertos com NT de 20 - 25 micras de espessura e massa de $17 \mathrm{~g} / \mathrm{m}^{2}$, aplicado dire- 
Tabela 1. Porcentagem de brotação, número de folhas e comprimento da parte aérea de mudas de mandioquinha-salsa tratadas com "Stimulate Mo", com e sem cobertura de Tecido "Não Tecido" (NT). Ponta Grossa, UEPG, 1998.

\begin{tabular}{lcccccc}
\hline $\begin{array}{c}\text { "Stimulate } \\
\text { Mo" }\end{array}$ & \multicolumn{2}{c}{ Brotação (\%) } & \multicolumn{2}{c}{ N$^{\circ}$ de folhas } & \multicolumn{2}{c}{ Parte aérea (cm) } \\
\hline \multicolumn{1}{c}{ Doses } & Com NT & Sem NT & Com NT & Sem NT & Com NT & Sem NT \\
\hline 0 & 96,67 & 88,00 & 2,27 & 2,00 & 10,77 & 7,93 \\
$2,5 \mathrm{ml} / \mathrm{L}$ & 98,00 & 89,33 & 2,27 & 2,00 & 10,73 & 7,30 \\
$5,0 \mathrm{ml} / \mathrm{L}$ & 97,00 & 92,00 & 2,55 & 2,00 & 12,67 & 7,70 \\
$7,5 \mathrm{ml} / \mathrm{L}$ & 90,67 & 90,33 & 2,55 & 2,00 & 10,57 & 7,80 \\
$10,0 \mathrm{ml} / \mathrm{L}$ & 96,67 & 95,00 & 2,83 & 2,00 & 11,10 & 8,40 \\
\hline Média & $95,80 \mathrm{~A}$ & $90,93 \mathrm{~B}$ & $2,49 \mathrm{~A}$ & $2,00 \mathrm{~B}$ & $11,17 \mathrm{~A}$ & $7,83 \mathrm{~B}$ \\
\hline CV (\%) & \multicolumn{3}{c}{ 4,45,83 } \\
\hline
\end{tabular}

*Médias seguidas de mesma letra não diferem significativamente entre si no nível de 5\% de probabilidade, pelo teste de Tukey.

Tabela 2. Enraizamento de mudas de mandioquinha-salsa tratadas com Stimulate Mo, com e sem cobertura de Tecido "Não Tecido" (NT). Ponta Grossa, UEPG, 1998.

\begin{tabular}{lllcc}
\hline $\begin{array}{c}\text { "Stimulate } \\
\text { Mo" }\end{array}$ & \multicolumn{2}{c}{ Número de raízes } & \multicolumn{2}{c}{$\begin{array}{c}\text { Comprimento de raízes } \\
\text { (cm) }\end{array}$} \\
\hline \multicolumn{1}{c}{ Doses } & Com NT & Sem NT & Com NT & Sem NT \\
\hline 0 & 50,50 & 42,77 & 3,20 & 2,33 \\
$2,5 \mathrm{ml} / \mathrm{L}$ & 53,60 & 42,23 & 2,67 & 3,17 \\
$5,0 \mathrm{ml} / \mathrm{L}$ & 57,27 & 48,80 & 4,70 & 3,33 \\
$7,5 \mathrm{ml} / \mathrm{L}$ & 53,00 & 43,07 & 4,10 & 3,33 \\
$10,0 \mathrm{ml} / \mathrm{L}$ & 60,50 & 44,70 & 3,87 & 3,40 \\
\hline Média* & $54,97 \mathrm{~A}$ & $44,31 \mathrm{~B}$ & $3,71 \mathrm{~A}$ & $3,11 \mathrm{~B}$ \\
\hline CV (\%) & \multicolumn{3}{c}{17,05} \\
\hline
\end{tabular}

*Médias seguidas de mesma letra não diferem significativamente entre si, no nível de $5 \%$ de probabilidade, pelo teste de Tukey.

tamente sobre os canteiros, formando uma manta flutuante, fixada com solo colocado sobre as bordas da manta.

O plantio foi realizado em junho de 1998, na área experimental de Olericultura da Fazenda-Escola Capão da Onça, UEPG, Ponta Grossa (PR), utilizando irrigação por aspersão. Aos 36 dias do plantio avaliou-se a porcentagem de mudas com brotação, considerando-se aquelas com brotação da parte aérea e, numa amostra de 7 plantas por repetição, avaliaram-se o número e comprimento médio das folhas e das raízes.

O delineamento experimental foi o de blocos casualizados, com três repetições, utilizando-se o esquema fatorial de 5 x 2 (cinco doses de "Stimulate Mo", na presença e ausência da cobertura com NT). Fez-se análise de regressão dos dados de doses de "Stimulate Mo" e, para comparação das médias relativas à proteção ou não com NT, usou-se o teste de "F".

\section{RESULTADOS E DISCUSSÃO}

Os fatores doses de "Stimulate Mo" e proteção com NT tiveram atuações independentes, não ocorrendo interação significativa entre eles nas características avaliadas.

Nas parcelas com proteção de NT observou-se desenvolvimento mais rápido e uniforme da parte aérea (Tabela 1). Aos 36 dias do plantio, mais de $95,0 \%$ das mudas apresentavam brotação da parte aérea, com maior número de folhas e comprimento maior que $10 \mathrm{~cm}$, enquanto nas parcelas não cobertas, ocorreu $90,9 \%$ de mudas com brotação, e estas apresentavam menor crescimento. $\mathrm{O}$ efeito superior do NT também foi verificado no número e no comprimento de raízes (Tabela 2 e Figuras $1 \mathrm{e} 2$ ).

As doses de "Stimulate Mo" não promoveram diferença significativa nas características de desenvolvimento da parte aérea (Tabela 1). Por outro lado, a aplicação de "Stimulate Mo" aumentou o número e o comprimento das raízes, com efeito linear para número (Figura 1) e quadrático para comprimento (Figura 2), tendo sido estimado como ponto de máximo, a dose de 7,0 ml/L. Não foram observados sintomas de fitotoxidez em quaisquer das doses estudadas. Estes resultados confirmam a atuação do produto como estimulador do sistema radicular, podendo resultar na maior capacidade de absorção de água e nutrientes (Stoller do Brasil, 1998).

Apesar da brotação e do enraizamento terem ocorrido durante os meses de junho, com temperaturas relativamente baixas (médias das máximas de $26,2^{\circ} \mathrm{C}$ e mínimas de $9,4^{\circ} \mathrm{C}$ ), não foram observadas mudas com haste floral em quaisquer dos tratamentos, provavelmente em função da idade das mudas e da seleção feita. Estes resultados corroboram com os obtidos por Silva \& Normanha (1964) e EMBRATER/ EMBRAPA (1982). Embora, Câmara (1992) não tenha encontrado diferenças na taxa de florescimento em função da posição do propágulo na planta.

A cobertura com NT resultou em médias superiores em todas as características avaliadas, quando comparada ao tratamento sem proteção (Tabelas 1 e 2). A proteção deve alterar fatores 
ambientais sob a cobertura, ocorrendo um microclima mais favorável para o desenvolvimento das mudas. Salientase que um dos objetivos do uso do NT nos cultivos que ocorrem nas épocas frias, é o aumento da temperatura noturna do ar abaixo da cobertura, de 2 a $5^{\circ} \mathrm{C}$, como os descritos por Hernandez \& Castilla (1993) e Otto (1997).

Os resultados demonstram que o pré-enraizamento de mudas de mandioquinha-salsa com o produto "Stimulate Mo" foi eficiente, aumentando o número e o comprimento de raízes de acordo com o aumento da dose até o limite de 7,0 ml/L.

Qualquer das técnicas estudadas vem reforçar o uso do pré-enraizamento, podendo-se obter mudas aptas para o transplante em curto espaço de tempo (36 dias), enquanto que, em condições normais, o tempo é de 45 a 60 dias (Santos, 1997).

\section{LITERATURA CITADA}

BRUNE, S.; GIORDANO, L de B.; LOPES,C.A.; MELO, P.E de. Tratamento químico de mudas de mandioquinha-salsa. Horticultura Brasileira, Brasília, v. 14, n. 2, p. 207-210, nov., 1996.

CÂMARA, F.L.A. Efeitos do substrato e da imersão em IBA, sobre o enraizamento de propágulos de mandioquinha-salsa. Horticultura Brasileira, Brasília, v. 7, n. 1, p.44, maio, 1989. Resumo.

CÂMARA, F.L.A. Enraizamento e produção de mandioquinha-salsa em função da posição do propágulo na touceira. Horticultura Brasileira, Brasília, v. 10, n. 1, p. 42, maio, 1992.

CARVALHO, A.C.P.P. de; LEAL, M.A.A. Efeito da utilização do hormônio AIB na capacidade de brotação e na sobrevivência de mudas de mandioquinha-salsa. Horticultura Brasileira, Brasília, v. 15, n. 1, maio, 1997. Suplemento. Resumo.

CASALI, V.W.D.; SEDIYAMA, M.A.N.; CAMPOS, J.P. Métodos culturais da mandioquinhasalsa. Informe Agropecuário, Belo Horizonte, v. 10, n. 120, p. 26-28, 1984.

EMBRATER/EMBRAPA. Sistemas de produção para a cultura da mandioquinha-salsa. Belo Horizonte, 1982. 33 p. (Sistema de produção. Boletim, 9)

HEMPHILL, D.D.; CRABTREE, G.D. Growth response and weed control in slicing cucumber under rowcovers. Journal of American Society for Horticultural Science, v. 113, n. 1, p. 41 45, 1988.

HERMANN, M.; HELLER, J. ed. Andean roots and tubers: ahipa, arracacha, maca and yacon. Rome: IPGRI, 1997. 256 p. (IPGRI, Promoting the conservation and use of underutilized and neglected crops, 21).

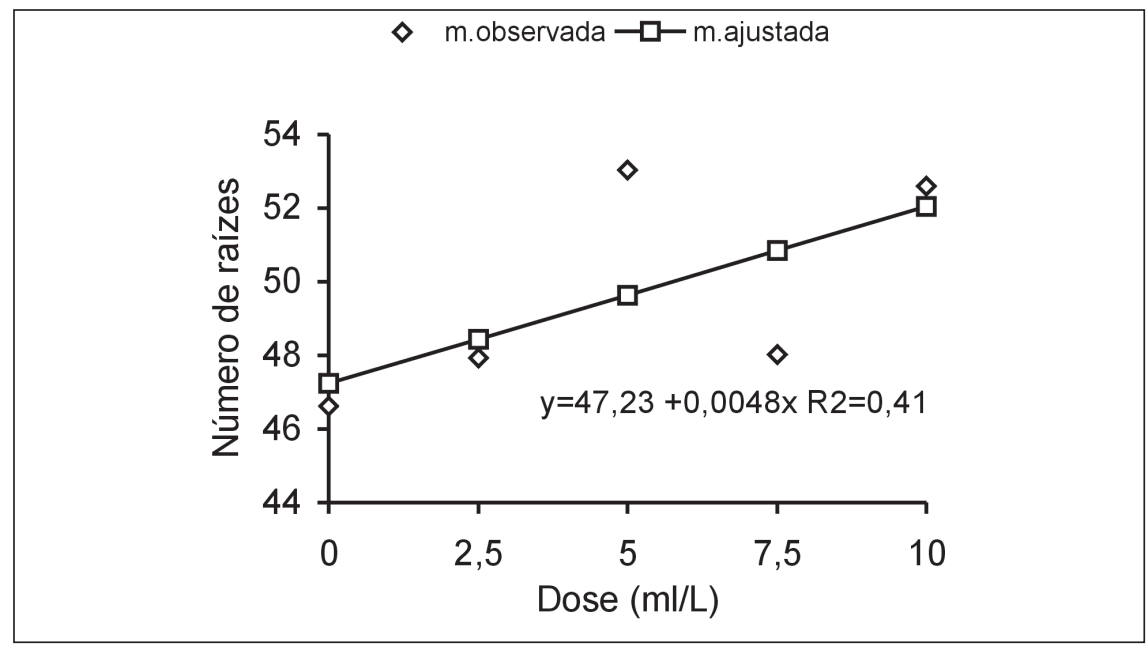

Figura 1. Efeito de doses de "Stimulate Mo" no número de raízes de mudas de mandioquinhasalsa. Ponta Grossa, UEPG, 1998.

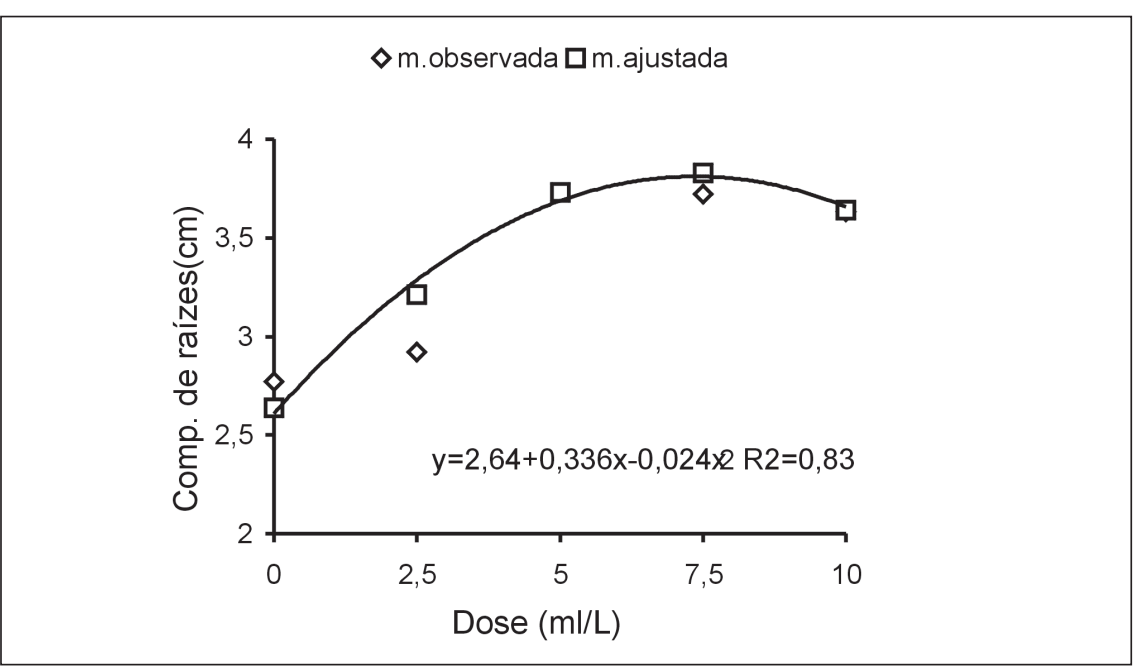

Figura 2. Efeito de doses de "Stimulate Mo" no comprimento de raízes (cm) de mudas de mandioquinha-salsa. Ponta Grossa, UEPG, 1998.

HERNÁNDEZ, J.; CASTILLA, N. E semiforzado con cubiertas flotantes. Hortofruticultura, v. 4, p. 34-36, 1993.

OTTO, R.F. Cubiertas de agrotextil en especies horticolas: balances térmicos, evapotranspiración y respuestas productivas. Córdoba: Universidad de Córdoba, 1997. 157 p. (Tese doutorado).

SANTOS, F.F. dos. Utilização de mudas juvenis e do pré-enraizamento no impedimento da floração em mandioquinha-salsa. Informe Agropecuário, Belo Horizonte, v. 19, n. 190, p. 27-34, 1997.

SEAB (Secretaria de Estado da Agricultura e do Abastecimento do PR). Departamento de Economia Rural - Deral, Levantamento da produção agrícola do Estado, safra 96/97, 1998.

SENNA NETO, N. Cultura da mandioquinha-salsa. Governador Valadares: PROHORT, 1976. 14 p. (EMATER-MG, Série Olericultura, 1).

SILVA, J.R.; NORMANHA, E.S. Instruções para a cultura da mandioquinha-salsa ou batatabaroa. Campinas: IAC, 1964. 9 p. (Boletim, 134).
SOLTANI, N.; ANDERSON, J.L.; HANSOM, A.R. Growth analysis of watermelon plants grown with mulches and rowcovers. Journal of the American Society for Horticultural Science, v. 120, p. 1001-1009, 1995.

STOLLER DO BRASIL. Stimulate Mo em hortaliças. Informativo Técnico, Stoller do Brasil, Divisão Arbore, jan/98.

VIEIRA, M.C.; HEREDIA, N.A.Z.; CASALI, V.W.D.; SIQUEIRA, J.G. Efeito de tipos, tamanhos e enterrio de mudas sobre o crescimento e produção de mandioquinha-salsa. In: ENCONTRO DE INICIAÇÃO CIENTÍFICA, 4, 1995, Dourados, Mato Grosso do Sul. Resumos... Dourados: UFMS, p. 237, 1995.

WELLS, O.S.; LOY, J.B. Intensive vegetable production with row covers. HortScience, v. 20, n. 5, p. 822-826, 1985.

Hortic. bras., v. 18, n. 1, mar. 2000 